[Agr. Biol. Chem., Vol. 34, No. 9, p. 1308 1313, 1970]

\title{
Availability of Energy in Alcohols, Aldehydes and Ketones by Growing Chicks
}

\author{
By Minoru Yoshida, Hiroshi Morimoto, ${ }^{*}$ Masanao Matsui ${ }^{* *}$ \\ and Ryohei ODA*** \\ National Institute of Animal Industry \\ * Japan Scientific Feeds Association \\ **Faculty of Agriculture, Tokyo University \\ ***Faculty of Technology, Kyoto University \\ Received February 9, 1970
}

\begin{abstract}
Biological availability of 23 alcohols, 16 aldehydes and 2 ketones was compared by the mini-test with chicks. Chicks can utilize methanol and ethanol, but not the alcohols of carbon chain from 3 to 9. Lauryl and myristyl alcohols were well utilized but those of higher carbon chain than 14 were not, mainly due to low digestibility. Glycerol and Dsorbitol were well utilized but not 4 other poly alcohols tested. Aldehydes and ketones with free carbonyl group showed low availability or even toxicity, but their derivatives with masked group showed no detrimental effect. Acetaldehyde, acetal and aldehydes of carbon chain longer than 9 were partially utilized.
\end{abstract}

This is the second paper of the studies on the possibility of various chemicals as energy sources of poultry feed. In the previous paper," biological availability of 54 aliphatic mono-, di- and tri-carboxylic acids was compared by bioassay procedure, mini-test, developed specifically for this purpose."

In this paper, similar comparison on biological availability was reported on 23 alcohols, 16 aldehydes and 2 ketones.

\section{EXPERIMENTAL}

Test material. Among 41 materials tested in this paper, 5 polyalcohols, i.e. 1,2-dimethylol cyclopropane, D-sorbitol, trimethylol propane, 2,2,6,6-tetramethylol cyclohexanol and vinyl alcohol polymer were prepared in Oda's Laboratory, Kyoto University; 3 aldehydes, i.e. lauryl, myristyl and stearyl aldehydes, were

1) M. Yoshida, H. Morimoto and R. Oda, Agr. Biol. Chem., 34, 1301 (1970).

2) M. Yoshida and H. Morimoto, ibid., 34, 684 (1970). synthesized in Matsui's Laboratory, Tokyo University; paraacetaldehyde was purchased and purified by distillation; and parapropionaldehyde was synthesized in Yoshida's Laboratory, National Institute of Animal Industry. All of the other samples were obtained as reagents, whose grades were shown in Note in Tables I and II.

Gross energy of the test materials was determined by an automatic bomb calorimeter, CA-1 manufactured by Shimadzu Seisakusho.

Bioassay. Details of the procedure of bioassay were exactly the same to those reported in the previous 2 papers.1,2) Standard dose-response curve was so prepared that available energy of the test material was estimated directly on the curve.

Among the samples tested, methyl, ethyl, propyl, $n$ - and isobutyl alcohols, isobutyl aldehyde and paraacetaldehyde were infused directly into crop. Since some of these samples had low solubility to water, $0.5 \%$ of detergent, Lipon F produced by Lion Yushi Co., was used to make the solution emulsified. All of the other samples tested were given orally being mixed in the diet at $5 \%$ level. Procedure of the determination of digestibility was also the same as that reported in the previous paper. ${ }^{1}$ 


\section{RESULTS AND DISCUSSION}

The data on alcohols were summerized in Table I.

Chicks can apparently utilize energy in methyl and ethyl alcohols which were given into crop as 10,0 aqueous solution. Very slight symptoms showing that chicks were intoxicated were observed at this feeding condition, and chicks took diet normally as shown by palatability index. Preliminary tests revealed that one $\mathrm{ml}$ of $25 \%$ solution of ethyl alcohol made chicks drunken and they then fell down asleep for several hours, that one $\mathrm{ml}$ of $50 \%$ solution of ethyl alcohol made chicks fell down and sleep overnight, and that one $\mathrm{ml}$ of $95 \%$ ethyl alcohol made chicks asleep and they never woke up again. According to these preliminary findings, all of the test materials were infused as $10 \%$ aqueous solution into crop when they were expected to be lost by evaporation from the diet.

Chicks infused one $\mathrm{ml}$ of $10 \%$ solution of propyl alcohol were heavily drunken and lost appetite; growth rate was retarded as shown by negative availability. Chicks infused one $\mathrm{ml}$ of $10 \%$ solution of either $n$ - or isobutyl

Table I. Gross Energy, Availability, Palatability and Digestibility OF ALCOHOLS

\begin{tabular}{|c|c|c|c|c|c|c|c|c|}
\hline Sample & & $\begin{array}{l}\text { No, of } \\
\text { chicks }\end{array}$ & $\begin{array}{c}\text { Gross } \\
\text { energy } \\
\text { kcal/g }\end{array}$ & $\begin{array}{l}\text { Avail- } \\
\text { able } \\
\text { energy } \\
\text { kcal/g }\end{array}$ & $\begin{array}{c}\text { Availa- } \\
\text { bility } \\
\text { AE/GE } \\
O_{0}\end{array}$ & $\begin{array}{l}\text { Palata- } \\
\text { bility } \\
\text { index }\end{array}$ & $\begin{array}{c}\text { Digesti- } \\
\text { bility } \\
\text { coeff. } \\
\text { ó }\end{array}$ & Note \\
\hline Methyl & $\mathrm{C}_{\mathrm{I}}$ & 4 & 4.88 & 3.9 & 80 & 98 & & Special $^{b}$ \\
\hline Ethyl & $\mathrm{C}_{2}$ & 4 & 6.89 & 1.5 & 22 & 100 & & 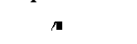 \\
\hline Propyl & $\mathrm{C}_{3}$ & 4 & 7.75 & -2.0 & - & 67 & & $"$ \\
\hline n-Butyl & $\mathrm{C}_{4}$ & $1 / 4^{0}$ & 8.44 & $x^{d 1}$ & - & 50 & & - \\
\hline$i$-Butyl & $\mathrm{C}_{4}$ & $1 / 4$ & 8.42 & x & - & 60 & & - \\
\hline tert-Butyl & $\mathrm{C}_{4}$ & 4 & 7.93 & -5.7 & - & 86 & & $\pi$ \\
\hline$n$-Hexyl & $\mathrm{C}_{6}$ & 4 & 9.19 & -5.0 & - & 86 & & $"$ \\
\hline n-Heptyl & $\mathrm{C}_{7}$ & 11 & 9.42 & -1.4 & - & 64 & 100 & Reagent ${ }^{b}$ \\
\hline$n$-Octyl & $\mathrm{C}_{8}$ & $2 / 9$ & 9.74 & $x$ & - & 52 & 100 & Special \\
\hline sec-Octyl & $\mathrm{C}_{8}$ & 4 & 9.56 & 1.0 & 10 & 60 & & Reagent \\
\hline 2-Et-Hexyl & $\mathrm{C}_{8}$ & 4 & 9.74 & -12.1 & - & 71 & & " \\
\hline$n$-Nonyl & $\mathrm{C}_{9}$ & 10 & 9.76 & -6.5 & - & 52 & 100 & " \\
\hline$n$-Decyl & $\mathrm{C}_{10}$ & 12 & 9.86 & 3.2 & 32 & 71 & 96 & " \\
\hline Lauryl & $\mathrm{C}_{12}$ & 11 & 9.99 & 11.2 & 112 & 75 & 96 & Special \\
\hline Myristyl & $\mathrm{C}_{14}$ & 11 & 10.03 & 9.5 & 94 & 64 & 88 & Reagent \\
\hline Cetyl & $\mathrm{C}_{16}$ & 4 & 10.22 & 2.4 & 23 & 91 & 26 & Special \\
\hline Stearyl & $\mathrm{C}_{18}$ & 4 & 10.28 & 4.8 & 47 & 98 & & $"$ \\
\hline Glycerol & $\mathrm{C}_{3}$ & 4 & 4.17 & 6.7 & 160 & 98 & & $" 1$ \\
\hline 1,2-Dimethylol cyclopropane & $\mathrm{C}_{5}$ & $1 / 1$ & & $x$ & - & 54 & & a. \\
\hline D-Sorbitol & $\mathrm{C}_{6}$ & 4 & 4.01 & 3.9 & 97 & 100 & & $a \vdash$ \\
\hline Trimethylol propane & $\mathrm{C}_{6}$ & 4 & 6.41 & -14.9 & - & 52 & & al \\
\hline $2,2,6,6$-Tetramethylol cyclohexanol & $\mathrm{C}_{10}$ & 4 & 6.04 & -3.4 & - & 54 & & a) \\
\hline Vinyl alcohol polymer & & 1 & & -19.4 & - & 54 & & a) \\
\hline
\end{tabular}


alcohols were intoxicated heavily and lost appetite; one chick out of 4 of each group died. As reported previously, ${ }^{3 /}$ chicks can efficiently utilize 1,2-propanediol and 1,3butanediol, which are relative diols to propyl and butyl alcohols, respectively. Availability of propionic and butyric acid, on the other hand, was unexpectedly low as reported previously." With these observations, it is certainly interesting to study whether or not propyl and butyl alcohols, when given by the other procedures than direct infusion of aqueous solution, can be available to chicks.

Miyazaki" reported that rats could utilize ethyl, propyl, butyl and isoamyl alcohols, even when these alcohols were mixed at the level of 20.0 in the diet. Rats were reported to be normal and no sign of intoxication by the alcohols was observed. Since our preliminary studies revealed that about $80 \%$ of these alcohols mixed in the diet was lost by evaporation within $24 \mathrm{hr},{ }^{31}$ these alcohols have to be infused directly into crop under the experimental conditions of mini-test to avoid the loss by evaporation. Therefore, it may not be reasonable to compare the data on rats with those on chicks.

All of the alcohols other than methyl, ethyl, propyl, butyl and isobutyl alcohol, were given orally being mixed in the diet. As shown in Table I, chicks apparently can not utilize energy in the alcohols of straight carbon chain between 5 to 9 . The findings are quite agreeable with those reported by Miyazaki ${ }^{5}$ that rats can not utilize alcohols with carbon chain longer than 6 .

To our great surprize, chicks can utilize energy in alcohols with carbon chain length between 10 to 14. Especially, availability and digestibility of lauryl alcohol was quite satisfactory, though palatability was slightly low,

3) M. Yoshida, H. Hoshii and H. Morimoto, Japan. Poultry Sci, 6, 73 (1969).

4) M. Miyazaki, Nippon Nogeikagaku Kaishi, 29, 497 (1955).

5) M. Miyazaki, ibid., 29, 501 (1955). being 75. These findings on lauryl alcohol were comparable to those on lauric acid reported previously. '" Contrary to these findings, Miyazaki ${ }^{5 \prime}$ reported that rats could not utilize higher alcohols and detrimental effect of dietary alcohols was getting severer with the increase in carbon chain length of alcohols. The difference between chicks and rats in the ability to utilize higher alcohols is very interesting and the data shown in Table I should be reconfirmed by long-term feeding experiments.

Low digestibility of cetyl alcohol was certainly main reason of its low availability by chicks. Since digestibility of alcohols higher than 12 decreased inversely with the increase in carbon chain length of alcohols, digestibility of stearyl alcohol was suspected to be lower than that of cetyl alcohol and low availability of stearyl alcohol with good appetite might be due to low digestibility. The findings again are agreeable with those on rats reported by Miyazaki, ${ }^{5}$ who estimated the digestibility of octyl, cetyl and stearyl alcohol being 99.5, 52.3 and 19.496 , respectively.

Combining the observations on fatty acids reported in the previous paper, ${ }^{11}$ it is certain that young chicks such as used in these minitests can not absorb completely the compounds of carbon chain length longer than 14 or 16 .

Alcohols with side chain, i.e. tert-butyl and 2-ethylhexyl alcohol, were not utilized by chicks. The findings were comparable to those reported previously that chicks could not utilize pivalic acid, $\left(\mathrm{CH}_{3}\right)_{3} \mathrm{C} \cdot \mathrm{COOH}$, and 2-ethyl-hexanoic acid. Rats were also reported to be unable to utilize tert-butyl alcohol efficiently. ${ }^{41}$

There may be no wonder in that chicks can utilize energy in glycerol, the constituent of natural fat, efficiently.

Trimethylol propane looked like toxic as shown by negative available energy in Table I. 1,2-Dimethylol cyclopropane killed the chick within 2 days, although only one chick was used in the test, since only $5 \mathrm{~g}$ of the sample was available. 2,2,6,6-Tetramethylol 
Table II. Gross Energy, Avallability, Palatability and Digestibility OF ALDEHYDES AND KETONES

\begin{tabular}{|c|c|c|c|c|c|c|c|c|}
\hline Sample & & $\begin{array}{l}\text { No. of } \\
\text { chicks }\end{array}$ & $\begin{array}{l}\text { Gross } \\
\text { energy } \\
\mathrm{k} \text { cal/g }\end{array}$ & $\begin{array}{l}\text { Avail- } \\
\text { able } \\
\text { energy } \\
\mathrm{kcal} / \mathrm{g}\end{array}$ & $\begin{array}{c}\text { Availa- } \\
\text { bility } \\
\text { AE/GE } \\
\end{array}$ & $\begin{array}{l}\text { Palata- } \\
\text { bility } \\
\text { index }\end{array}$ & $\begin{array}{c}\text { Digesti- } \\
\text { bility } \\
\text { coeff. } \\
\text { \% }\end{array}$ & Note \\
\hline Glycolaldehyde & $\mathrm{C}_{2}$ & $\left.2 / 2^{a}\right)$ & & $x^{a}$ & 一 & 3 & & Reagent ${ }^{a}$ \\
\hline DL-Glycer- & $\mathrm{C}_{3}$ & 1 & & -15.6 & - & 24 & & $"$ \\
\hline Dihydroxy acetone & $\mathrm{C}_{3}$ & 8 & 3.50 & -0.1 & - & 95 & & $\mathrm{BDH}^{b}$ \\
\hline i-Butylaldehyde & $\mathrm{C}_{4}$ & $3 / 4$ & & x & - & - & & Reagent \\
\hline Glutar- " & $\mathrm{C}_{5}$ & $2 / 2$ & 1.36 & $x$ & - & 13 & & First $b 1250$ soln. \\
\hline n-Hexyl- " & $\mathrm{C}_{6}$ & 4 & 8.00 & -3.0 & - & 68 & & $\mathrm{BDH}$ \\
\hline n-Heptyl- " & $\mathrm{C}_{7}$ & 4 & 8.96 & -2.0 & - & 87 & & " \\
\hline$n$-Octyl- $\quad " \prime$ & $\mathrm{C}_{8}$ & 4 & 9.49 & -4.2 & - & 53 & & $n$ \\
\hline$n$-Nontl- " & $\mathrm{C}_{9}$ & 4 & 9.67 & 2.8 & 29 & 66 & & Reagent \\
\hline$n$-Decyl- " & $\mathrm{C}_{10}$ & 4 & 9.73 & 4.1 & 42 & 71 & & $"$ \\
\hline Lauryl- " & $\mathrm{C}_{12}$ & 8 & 9.92 & 6.3 & 64 & 88 & 51 & c) \\
\hline Myristyl- " & $\mathrm{C}_{14}$ & 8 & 9.98 & 7.4 & 74 & 89 & 53 & c) \\
\hline Stearyl- " & $\mathrm{C}_{18}$ & 8 & 10.22 & 4.9 & 48 & 91 & 58 & c) \\
\hline Acetaldol & $\mathrm{C}_{4}$ & $8 / 8$ & 5.98 & $x$ & - & - & & $\mathrm{BDH}$ \\
\hline Diacetone alcohol & $\mathrm{C}_{6}$ & 8 & 7.30 & $-d i$ & - & 66 & & Reagent \\
\hline Acetal & $\mathrm{C}_{6}$ & 16 & 7.48 & 4.8 & 64 & 93 & & $"$ \\
\hline Paraacetaldehyde & $\mathrm{C}_{6}$ & 8 & 5.97 & 2.9 & 49 & 91 & & c) \\
\hline Parapropionaldehyde & $\mathrm{C}_{9}$ & 12 & 7.23 & -2.1 & - & 90 & & c) \\
\hline
\end{tabular}

a) See footnotes of Table I.

b) First: first grade reagent; BDH: obtained from the British Drug Houses, Ltd.

c) See text.

d. Chicks lose body weight.

cyclohexanol also looked like toxic, as shown by negative available energy in Table I. These methylol compounds depressed the appetite of the chicks.

Chicks could efficiently utilize energy in Dsorbitol, which is one of sugar alcohols, with good appetite.

The chick on vinyl alcohol polymer gained body weight in the initial 5 days, but lost body weight at 6 th day. The data suggested that vinyl alcohol polymer might not be toxic but low palatability of the chick made body weight lost as glycolic and azelaic acid did." Although only one chick was used in this mini-test, an information indicating that chicks have a limited ability to utilize energy in polymers, was added to those obtained with polymers of ethanediol and propanediol in the previous paper. ${ }^{3}$
The data on aldehydes and ketones were summarized in Table II.

It was hard to understand why chicks died on glycolaldehyde and why the availability of glyceraldehyde and dihydroxyacetone by chicks was negative, since glycolaldehyde is one of the simplest carbohydrates, except formaldehyde, and glyceraldehyde-3-phosphate and dihydroxyacetone-phosphate are known as moieties of fructose-1,6-diphosphate split by aldolase in anaerobic metabolism of carbohydrate. However, it was observed that the diet containing $5 \%$ of glycolaldehyde turned to brownish yellow after 6 days of experimental period. Therefore, it was most likely that some chemical reaction might take place in the diet, by which these aldehydes themselves together with other dietary nutrients were decomposed, producing detrimental bypro- 
ducts in the diet.

The suspicion was confirmed by feeding glutaraldehyde to chicks. This sample was obtained and mixed in the diet as $25 \%$ solution. Soon after the sample was mixed, the color of the test diet, usually being creamy white, changed into brown, and chicks fed the diet died within two days. It is well known, as Maillard or amino-carbonyl reaction, that carbonyl group in aldehyde reacts with amino group in protein, resulting in brown product. Gertainly, other possible chemical reactions may take place in the diet containing free carbonyl group. The speed of the reactions may be different among different chemicals, and therefore, the detrimental effect to the chicks within the experimental period of 6 days may be also different among the various samples tested.

In the previous paper, ${ }^{11}$ it was reported that growth retardation and extremely low palatability were observed in chicks fed either oxalacetic or $\alpha$-ketoglutaric acid, both of which are known as constituent elements of the tricarboxylic acid cycle in aerobic metabolism of carbohydrate, and therefore, expected to be utilized by chicks efficiently. Free carbonyl group in these acids must have reacted with the other dietary nutrients, producing detrimental product.

Only one exception was pyruvic acid, which has free carbonyl group but was utilized well. ${ }^{1}$ However, the diet containing the acid got offensive smell and the color changed from creamy white to yellowish brown toward the end of experimental period of 6 days. Therefore, it is most reasonable to expect that the growth of the chicks on the diet will be retarded if the feeding experiment be continued further.

Energy in acetal was available by chicks with good appetite. This may be due to the fact that carbonyl group of acetaldehyde is masked by two ethoxy groups in acetal. Therefore, no reactions might take place in the diet between carbonyl group and other nutrients and no detrimental effect to the chicks was observed. Good appetite on paraacetaldehyde and parapropionaldehyde may also rule out the possibility of such detrimental reaction in the diet, since carbonyl groups are masked by each other in para-form. However, the data shown in Table II revealed that the availability of these aldehydes by chicks was low. Contrary to these compounds whose carbonyl group was masked, acetaldol and diacetone alcohol, in which one of the two carbonyl groups was free, were actually toxic to the chicks.

The data on paraacetaldehyde given in Table II suggest that acetaldehyde may not only be toxic, but also its energy is partially available by the chicks. The findings are agreeable to those reported by Ozaki ${ }^{\prime \prime}$ and Ashida." Again, energy of propionaldehyde, having carbon chain of 3 , was not available by the chicks. This is just comparable to the data on propyl alcohol in Table I and propionic acid in the previous paper."

The detrimental effect of free carbonyl group seemed to decrease inversely with the increase in carbon chain length of aldehydes. Energy in aldehydes with carbon chain longer than 9 was partially available by chicks, but their low availability, 740 or less, may be partly due to their low digestibility. Low digestibility of laurylaldehyde was unexpected since the digestibilities of lauric acid and lauryl alcohol were determined to be 83 and $96^{\circ} \circ^{\prime}$, respectively.

$\mathrm{Ozaki}^{6}$ already described that nutritive value of aldehydes to rats increased with the increase in carbon chain length from 7 to 17 .

Isobutyl aldehyde and paraacetaldehyde when infused into crop as $10 \%$ aqueous solution made chicks severely intoxicated, and 3 and 2 chicks, respectively, among 4 chicks in each treatment died within 6 days of experimental period. However, no symptom of in-

6) J. Ozaki, Nippon Nôgeikagaku Kaishi,3, 977 (1927).

7) K. Ashida, private communication (1967). 
toxication was observed when paraacetaldehyde was mixed in the test diet, and chicks seemed to utilize energy in paraacetaldehyde partially as shown in Table II.

Summarizing, the availability of saturated alcohols of straight carbon chain, when mixed in the diet and fed to chicks, seemed to increase gradually with the increase in length of carbon chain. With carbon chain length longer than 10 , the availability became positive reaching the maximum at about 12 or 14 , i.e. lauryl or myristyl alcohols, and thereafter, the availability decreased with further increase of carbon chain length, mainly because of lowered digestibility. Similar tendency was observed in the availability of saturated, straight chain aldehydes as shown in Table II. Similar tendency was also suggested in the availability of saturated fatty acids reported in the previous paper, ${ }^{11}$ although in this case, availability of caproic acid, which has 6-carbon chain, was already fairly high.

However, as mentioned at the beginning of discussion in the previous paper, ${ }^{11}$ the bioassay procedure was miniaturized by sacrificing the accuracy of the estimate, although the procedure was so devised that the confidence interval of the estimates could be calculated if necessary. Especially, any chronic influence to the chicks can not be detected by this mini-test, since the experimental period is cut off to be only 6 days. Therefore, any definite conclusion should be given after the long-term feeding experiment to confirm the above discussion. The data on mini-tests indicate only the possibility. 